\title{
STATISTICAL ANALYSIS OF NON-CONFORMITES OF STEEL ROUND BARS
}

\author{
Krzysztof KNOP \\ Czestochowa University of Technology, Czestochowa, Poland, EU, krzysztof.knop@wz.pcz.pl
}

https://doi.org/10.37904/metal.2020.3652

\begin{abstract}
The article presents a statistical approach to the results of non-conformities of steel round bars over 12 months. Basic statistical measures, Pareto-Lorenz diagram, histograms, box plot, picture charts as well as correlation analysis were used to present the distribution of data regarding the number of non-conformities and dependencies in the analyzed data in a system according to the type of non-conformities found and in the time system - according to the examined months. The study aimed to analyze and discover statistical dependencies in the data on the number of non-conformities. An analysis was also made of the relationship between the factors affecting non-conformities and selected non-conformities, and activities for reducing non-conformities were identified. The share of identified non-conformities concerning the volume of production in the annual period was $0.25 \%$. A large diversity of data on non-conformities in individual months of the analysis was indicated. The dominant non-conformities over 12 months were wrinkle scratches, bar skewness and scratches due to rolling mill, while the critical month with the largest number of non-conformities was September, with the total number of non-conformities in the months examined being varied slightly. A lot of valuable information was obtained about the structure of steel round bars non-conformities. Statistical data were analyzed using the Statistica 13.0 program from TIBCO Software.
\end{abstract}

Keywords: Metallurgy, steel round bars, non-conformities, statistical analysis, Statistica software

\section{INTRODUCTION}

A non-conformance (or 'non-conformity') is a condition of a feature that means that the requirement has not been met [1]. The non-conformance could be in a service, a product, a process, goods from a supplier, or in the management system itself. To speak about non-conformity, it is necessary to have a reference criterion (a document specifying the requirements for the non-conformance object/service) and proof of non-conformity [2]. Non-conformity and non-conforming products it is not the same. The mere occurrence of a non-conforming product does not have to qualify it as a non-conforming unit. A non-conforming unit is a product that has a greater number of non-conformances (the intensity of non-conformance) than the allowable one, or a defect, i.e. a non-conformance, which does not allow the product to be fully usable. Every defect is a non-conformity, but not every non-conformity is a defect [3]. In the Six Sigma methodology, the basic measured value is the number of non-conformities (not the number of non-conforming units) detected in the production batch. The consumption of labor, materials, parts, and machines does not increase proportionally to the number of nonconforming units, but to the non-conformances (because they are repaired), so measures based on the number of non-conformances give a closer view about the costs of quality [4]. Modernly managed enterprises focus on the elimination of so-called "hidden factories", i.e. the phenomenon of the emergence of new, unofficial processes and systems that are used to repair the non-conformances that arise during the production process without registering this fact. Hidden factories bring with it productivity losses and additional costs that should be reduced. Therefore, the challenge is to produce good products the first time [5], which is not easy to achieve due to the multitude of factors affecting the quality results of the process, disrupting production without defects [6]. To achieve this goal include among others: error-proofing processes and solutions (jap. Poka-Yoke) are 
designed and implemented, standardization is carried out, effective preventive measures are taken and a continuous improvement process is carried out.

The product non-conformance analysis may concern quantitative and qualitative aspects [7]. In quantitative (valuable) terms, non-conformities are analyzed mainly due to the number of occurrences in the period considered, or the costs associated with them (internal and external). This analysis provides the basis for identifying critical non-conformities that should be eliminated first. Classic and modern quality tools are used as analysis tools [8], e.g. Pareto-Lorenz diagram, $A B C$ method, matrix diagram. In terms of qualitative (descriptive) non-conformities are analyzed mainly due to their causes and effects, their origin $(6 \mathrm{M}+\mathrm{E})$, root causes to determine appropriate remedial actions (limiting or eliminating their occurrence). The analysis tools are e.g. the Ishikawa diagram (4M), the 5WHY method, the FMEA method, the A3, 8D, QRQC, Quick Kaizen report, i.e. tools and methods for analyzing and improving quality [9]. The analysis begins with a thorough knowledge and description of the case of non-conformance $(5 \mathrm{~W} 1 \mathrm{H}, 5 \mathrm{G})$. The more information about nonconformity is known, the better they can be managed (reduced and eliminated). Quantitative data on cases of identified non-conformance, properly analyzed can say a lot about the nature of quality problems. For this purpose, it can be used statistics, and more specifically statistical analysis, which aims to detect regularities in the data obtained, determine their nature, discover basic patterns, relationships, or trends, and draw the right conclusions useful in science and practice [10]. Statistical visualization by fast, interactive statistical analysis and exploration capabilities with a graphical interface can be used to better understand any type of data, including qualitative data. Statistical analysis will not solve the problem but will let know the problem better. This knowledge can then be successfully used to improve a given problem area.

The aim of the article is a statistical analysis of non-conformities of round bars for quality improvement. Data on non-conformities of steel bars for a period of 12 months were analyzed using less and more advanced statistical analyzes. For statistical analysis and graphic interpretation of results, Statsoft 13.0 software was used.

\section{RESEARCH METHODOLODGY}

The examined object is a metallurgical plant with over 185 years of Polish metallurgy tradition specializing in the production of rolled and forged-rolled products. Among the numerous assortment of the smelter, the most important can be distinguished: pipe and forging slabs, billets for forging, pipe and cylinder bars, round bars, flat bars, head sections, angles, channel bars, hoops, rings, and forgings. The production volume classifies the steel mill to medium-sized steel mills, while the manufacturing assortment makes the steel mill an important plant in the supply of steel products to the machine-building, shipbuilding, construction, and many other industries, both on the domestic and foreign market.

The subject of research is to analyze the quality problems (non-conformities) in the manufacturing system of metallurgical products - round bars. The research aim is to determine what statistical relationships can be found by analyzing data on the number of round bars non-conformance in monthly and annual terms. Round bars are made in the tested steelworks as hot-rolled with 25 dimensions $(90 \div 250 \mathrm{~mm})$ and 5 tolerances $( \pm$ $1.3 \div \pm 3.0$ ) (according to EN 10060). The deviation from straightness is a maximum of $0.25 \%$ of the measured length. Round bars are made of carbon and alloy steels according to EN 10025; EN 10083; EN10084; EN 10273, DIN 17243, and others agreed when ordering. The share of the tested steel mill in the domestic production of rolled round bars with a diameter of over $90 \mathrm{~mm}$ is estimated at $45 \%$. In the production of rolled round bars with a diameter of over $150 \mathrm{~mm}$, the tested steel mill is the only domestic producer.

The data for statistical analysis were taken from the quality control department at the steel mill. 10 types of bars non-compliance were found and assigned to them from $\mathrm{N} 1$ to $\mathrm{N} 10$, where: $\mathrm{N}_{1}$ - Section or matrix overfill, $\mathrm{N}_{2}$ - Section or matrix unfilled, $\mathrm{N}_{3}-$ Bar twist, $\mathrm{N}_{4}$ - Bar corrugation, $\mathrm{N}_{5}$ - Skewness of the bar, $\mathrm{N}_{6}$ - Incorrect 
dimensions, $\mathrm{N}_{7}$ - Wrinkle scratches, $\mathrm{N}_{8}$ - Cracks of rolling origin, $\mathrm{N}_{9}$ - Scales, $\mathrm{N}_{10}$ - Bar ovality. Out of 1,250,600 manufactured bars, 3,144 were identified in which the non-conformities were $(0.25 \%)$.

The following statistical analyzes were carried out for the research objective:

- $\quad$ basic statistical measures were used, i.e. mean $\bar{x}$, median $M e$, first quartile $Q_{1}$, third quartile $Q_{3}$, range $R$, standard deviation $s$, coefficient of variation $V_{s}[10]$, for a synthetic description of the structure of nonconformances of bars according to their type and according to the examined months

- $\quad$ categorized picture charts, i.e. Chernoff's faces, were used to visualize hidden systems of interrelationships between individual types of non-conformities and between the months studied. Shapes and sizes of individual facial features were assigned relative values of the number of all nonconformities in a given month (time analysis) or the value of occurrence of a given non-conformities in subsequent months (analysis by types of non-conformity). Facial features representing individual months / non-conformities are January / $\mathrm{N}_{1}$ : face width, February / $\mathrm{N}_{2}$ : ear height, March / $\mathrm{N}_{3}$ : half-face height, April / $\mathrm{N}_{4}$ : eccentricity of the upper half face, May / $\mathrm{N}_{5}$ : eccentricity of the lower half face, June / $N_{6}$ : nose length, July / $N_{7}$ : location of the middle of the mouth, August / $N_{8}$ : the curvature of the mouth, September / $\mathrm{N}_{9}$ : mouth length, October / $\mathrm{N}_{10}$ : height of the ear line, November: skewed eye, December: eye tilt,

- a histogram and a box-plot of median - quartiles - range were used to graphically illustrate the relationship between the location, dispersion, and shape of the data distribution regarding the number of non-conformities over the entire study period (1 year),

- $\quad$ Pareto-Lorenz diagram was used to indicate critical (the most occurring) non-conformities throughout the entire research period (1 year),

- Pearson's correlation coefficient and correlation table were used to determine the direction and strength of the relationship between all non-conformities at the significance level $\alpha=0.05$.

\section{RESULTS}

The results of the analysis of basic statistical measures for the data set regarding the number of nonconformities over 12 months, broken down by type of non-conformities are presented in Table 1.

Table 1 Statistical measures of the data set regarding steel bars non-conformities within a period of 12 months - analysis by type of non-conformities

\begin{tabular}{|c|c|c|c|c|c|c|c|c|c|c|}
\hline \multirow{2}{*}{ Symbol } & \multicolumn{10}{|c|}{ Descriptive statistics } \\
\cline { 2 - 12 } & Sum & $\bar{x}$ & Me & Min & Max & $\boldsymbol{Q}_{1}$ & $\boldsymbol{Q}_{\mathbf{2}}$ & $\boldsymbol{R}$ & $\boldsymbol{s}$ & $\boldsymbol{V}_{\boldsymbol{s}}$ \\
\hline $\mathbf{N}_{\mathbf{1}}$ & 225 & 18.75 & 14.5 & 3 & 55 & 6.5 & 28 & 52 & 15.66 & 83.50 \\
\hline $\mathbf{N}_{\mathbf{2}}$ & 178 & 14.83 & 11.0 & 3 & 30 & 8.0 & 25 & 27 & 9.23 & 62.24 \\
\hline $\mathbf{N}_{\mathbf{3}}$ & 195 & 16.25 & 14.5 & 5 & 34 & 8.5 & 22 & 29 & 10.06 & 61.88 \\
\hline $\mathbf{N}_{\mathbf{4}}$ & 342 & 28.50 & 27.5 & 4 & 55 & 16.5 & 39 & 51 & 16.10 & 56.49 \\
\hline $\mathbf{N}_{\mathbf{5}}$ & 469 & 39.08 & 17.0 & 5 & 107 & 8.0 & 68 & 102 & 39.02 & 99.85 \\
\hline $\mathbf{N}_{\mathbf{6}}$ & 324 & 27.00 & 19.0 & 7 & 66 & 9.5 & 45 & 59 & 19.58 & 72.53 \\
\hline $\mathbf{N}_{\mathbf{7}}$ & 476 & 39.67 & 30.0 & 5 & 108 & 20.0 & 48 & 103 & 33.67 & 84.89 \\
\hline $\mathbf{N}_{\mathbf{8}}$ & 440 & 36.67 & 29.5 & 3 & 105 & 17.0 & 53 & 102 & 28.13 & 76.72 \\
\hline $\mathbf{N}_{\mathbf{9}}$ & 248 & 20.67 & 19.0 & 2 & 45 & 16.0 & 24 & 43 & 10.21 & 49.40 \\
\hline $\mathbf{N}_{\mathbf{1 0}}$ & 247 & 20.58 & 23.0 & 1 & 34 & 12.5 & 29 & 33 & 10.44 & 50.72 \\
\hline
\end{tabular}


The average number of non-conformities in the 12 months examined was the highest for $\mathrm{N}_{8}$ (36.67), the lowest - $N_{2}$ (14.83). The largest dispersion of the number of non-conformities was recorded for $N_{7}$ (103), $N_{5}$ (102) and $\mathrm{N}_{8}$ (102), the smallest - $\mathrm{N}_{2}$ (27). The average variation of the number of non-conformity around the mean value was the highest for $\mathrm{N}_{5}$ (39.02), the smallest $-\mathrm{N}_{2}$ (9.23). The relative variation of the number of non-conformity were the largest for $\mathrm{N}_{5}(99.85 \%)$, the smallest for $\mathrm{N}_{9}(49.40 \%)$. Analysis by time showed that the month with the highest average number of non-conformities was September (26.60), with the lowest - October (25.90). The largest dispersion of the number of occurrences of 10 non-conformities was recorded in the months of December (104), February (103), and April (102), the smallest in June (41). The average variation of the number of non-conformities around the mean value was the highest in December (31.15), the lowest in June (15.72). Relative variation was the largest in December (119.8\%), the smallest - in June $(60.46 \%)$.

The result of the analysis using Chernoff's face for data regarding non-conformities depending on the time (by subsequent months) and types of non-conformities is shown in Figure 1.
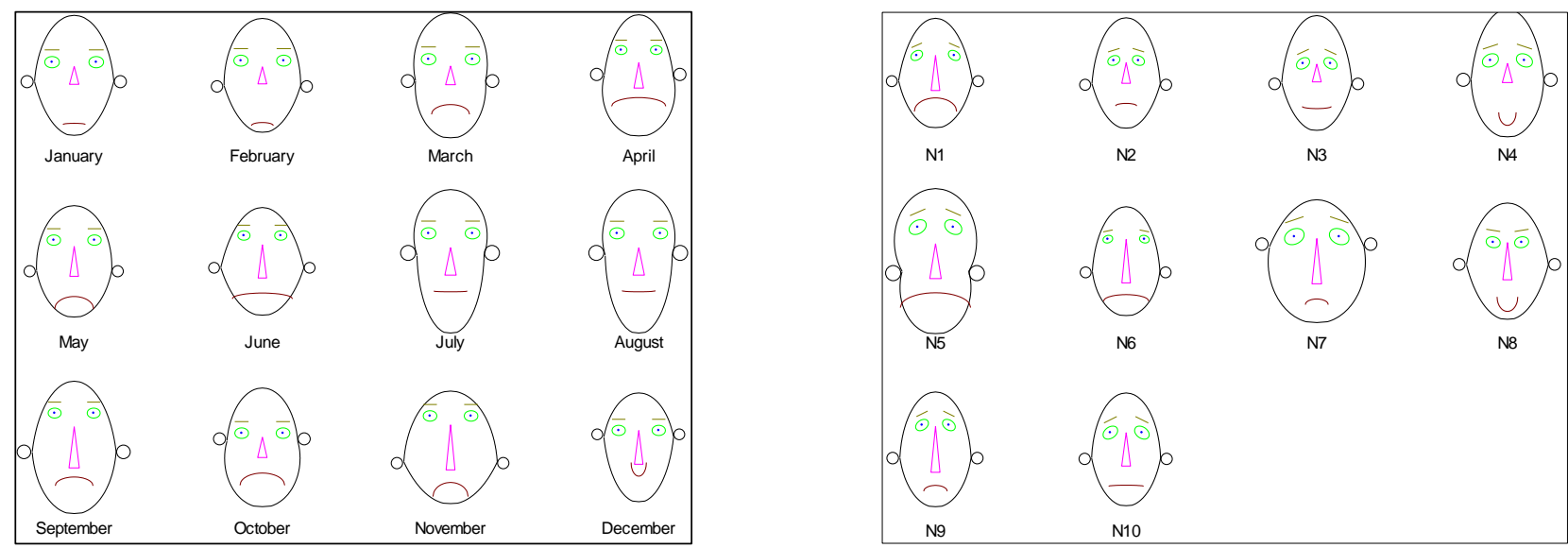

Figure 1 Chernoff's faces for the analysis of the number of non-conformities by months (left) and by types

The face analysis by month shows that the month of December, depending on the number of non-conformities $\mathrm{N} 8$, is completely unlike other months. It is represented by a face with a completely different mimicry than the others. This face is smiling, which means that the number of $\mathrm{N}_{8}$ non-conformity this month was the largest. The fact that the face is smiling does not mean that it is good, it just means that for a given case the variable has large values - in turn, "much" does not mean "good" in this case (non-conformities are analyzed). In turn, the month of October is represented by a relatively smallest face (the number of occurrences of nonconformities this month was the lowest). The face analysis by types of non-conformities shows that $\mathrm{N}_{7}$ nonconformity was the most frequent within 12 months (largest face) and $\mathrm{N}_{2}$ the least frequent (smallest face).

During the entire study period (12 months), 3144 cases of non-conformances were identified. The average number of occurrences of non-conformances each month is 27 , the maximum number is 108 (February, $\mathrm{N}_{7}$ ), the minimum is 1 (December, $\mathrm{N}_{10}$ ), i.e. the range was 107 . The number of non-conformities found differs on average from the mean by \pm 22.79 . Therefore, there was a large variation in the number of non-conformities throughout the period considered.

The box plot (Figure 2) indicates that $50 \%$ of cases of non-conformities are in the range $10-33.50 \%$ of the number of non-conformities were greater than 20 and $50 \%$ smaller. Outliers and extreme values are visible. Extreme values occurred in February $\left(\mathrm{N}_{7}-108\right)$ and in April ( $\left.\mathrm{N}_{5}-107\right)$, with outliers in March $\left(\mathrm{N}_{5}-80\right)$, January $\left(\mathrm{N}_{7}-102\right)$ and October $\left(\mathrm{N}_{5}-102\right)$. The histogram (Figure 2) of the distribution of the number of non-conformities is right-sided asymmetrical with the "hole". Most cases of non-conformities were between 0 and 10 (35). This is the desired behaviour of the distribution of the number of non-conformities (the less, the better), but with the 
greater the decrease the better. In the analyzed case, the distribution of the number of non-conformities covers as many as 9 categories.
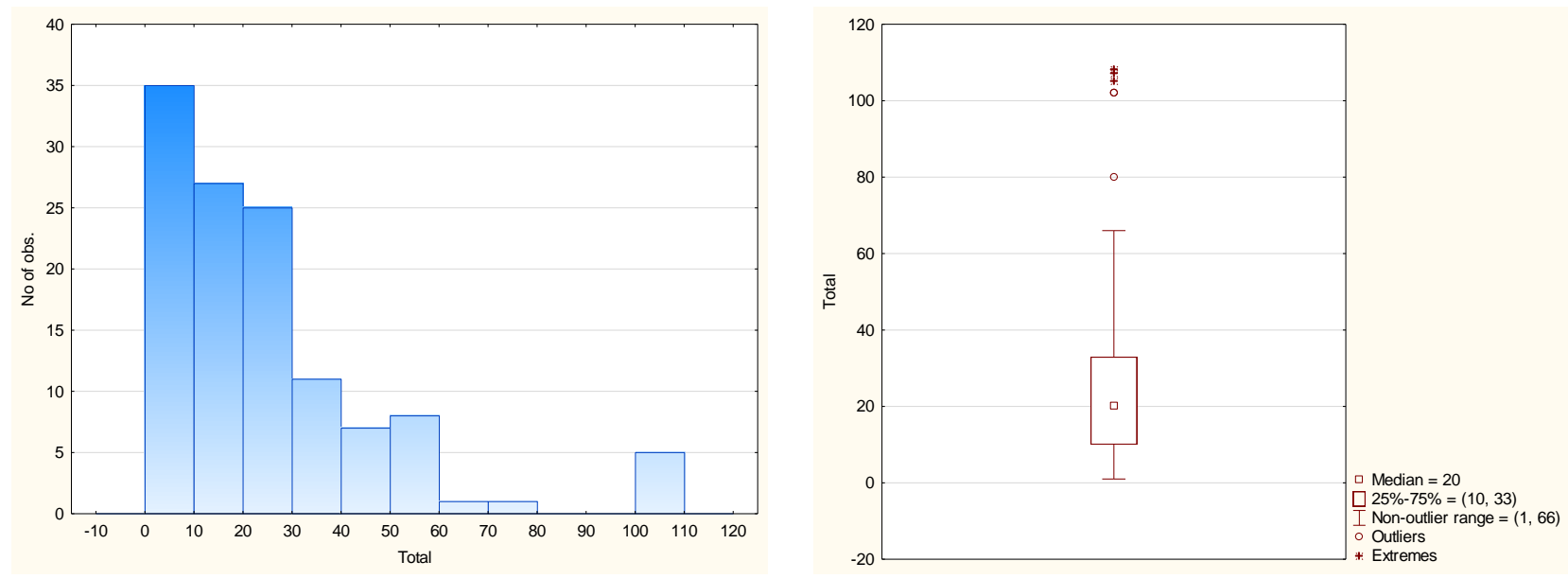

Figure 2 Histogram and box plot for the number of non-conformities of round bars over a period of 1 year

An analysis was made using the Pareto-Lorenz diagram to indicate critical non-conformities over a 12-month (Figure 3). The analysis shows that critical non-conformities are non-conformities marked with $\mathrm{N}_{7}, \mathrm{~N}_{5}, \mathrm{~N}_{8}$ and $\mathrm{N}_{4}$. Their cumulative share is $54.93 \%$. These are non-conformities that should be eliminated first.

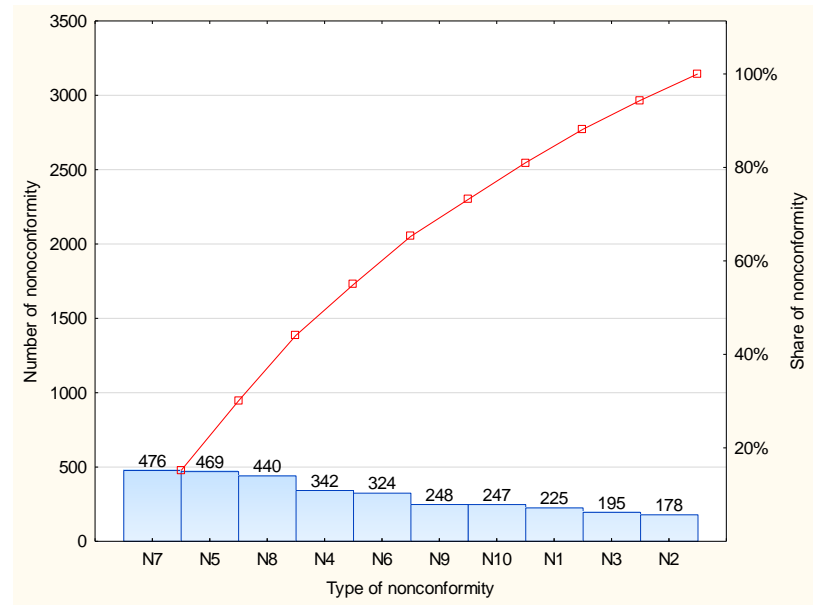

\begin{tabular}{|c|c|c|c|c|c|c|c|c|c|c|}
\hline & N1 & N2 & N3 & N4 & N5 & N6 & N7 & N8 & N9 & N10 \\
\hline $\mathrm{N} 1$ & 1.00 & & & & & & & & & \\
\hline N2 & $-0.70^{*}$ & 1.00 & & & & & & & & \\
\hline N3 & -0.46 & 0.42 & 1.00 & & & & & & & \\
\hline $\mathrm{N} 4$ & -0.44 & 0.30 & $0.60^{*}$ & 1.00 & & & & & & \\
\hline N5 & -0.28 & 0.06 & -0.04 & -0.24 & 1.00 & & & & & \\
\hline N6 & $0.68^{*}$ & -0.19 & -0.37 & -0.34 & -0.19 & 1.00 & & & & \\
\hline N7 & 0.23 & -0.52 & -0.38 & -0.05 & -0.45 & -0.36 & 1.00 & & & \\
\hline N8 & -0.42 & $0.63^{*}$ & 0.13 & 0.16 & -0.54 & -0.10 & 0.03 & 1.00 & & \\
\hline N9 & 0.06 & -0.31 & -0.17 & -0.39 & 0.25 & -0.04 & -0.01 & -0.49 & 1.00 & \\
\hline N10 & 0.28 & -0.25 & 0.44 & -0.07 & 0.05 & 0.34 & -0.45 & -0.43 & 0.43 & 1.00 \\
\hline
\end{tabular}

Figure 3 Pareto-Lorenz diagram of the steel bars non-conformities structure (left) and correlation table

The correlation analysis allowed to indicate statistically significant correlation relationships $(p<0.05)$ between 4 pairs of non-conformities: $N_{1}$ and $N_{2}(-0.70), N_{1}$ and $N_{6}(0.68), N_{2}$ and $N_{8}(0.63)$ and $N_{3}$ and $N_{4}(0.60)$. As the number of 'section overfill' non-conformities increases, the number of 'section unfilled' non-conformities (and vice versa) decreases significantly. The more cases of one non-conformity, the less the other in the months under consideration. These non-conformities, although they have common causes, are caused by different rolling temperatures (too high - $\mathrm{N}_{1}$, too low $-\mathrm{N}_{2}$ ), different section size (too small - $\mathrm{N}_{1}$, too large - $\mathrm{N}_{2}$ ) or incorrect shape of the charge [11]. With the increase in the number of non-conformity such as 'section unfilled', the number of 'cracks of rolling origin' increases (0.63). One of the reasons for 'cracks of rolling origin' is that the section is not filled. As the number of 'bar twist' non-conformities increases, the number of 'bar corrugation' non-conformities increases. These non-conformities have common causes in the examined steelworks, which include: bad attitude of the rollers, poor condition of the rolling mill, improper organization of work, insufficient qualifications of technical service. 


\section{CONCLUSION}

The article concerned the statistical analysis of data on non-conformities of round bars for a period of 12 months. With the use of less and more advanced statistical analyzes, it was attempted to obtain information on the structure of non-conformities, determine its nature, visualize hidden dependencies, connections in the obtained data on the number of non-conformities in the examined period. Critical non-conformities were indicated due to the number of occurrences, which were: wrinkle scratches, skewness of the bar, cracks of rolling origin and bar corrugation. It is these non-conformities that the company should deal with first in order to limit them. To do this, it must be addressed the root causes of these non-conformities, plan remedial actions, and check their effectiveness. The reasons for these non-conformities in the tested steel mill are: poor casting process, section unfilled, incorrect condition of the rolling mill, incorrect setting of the rolling mill, improper organization of work, insufficient qualifications of technical service. To prevent these non-conformities, additional employee training, ongoing maintenance of rolling mill machinery and equipment, and appropriate selection of steel should be carried out. The analyzes also showed that the number of occurrences of specific types of bar non-conformities in subsequent months was very diverse, where the greatest variability of results was recorded for the skewness of the bar. During the whole research period, the values of occurrences of nonconformities were visible, such as skewness of the bar, wrinkle scratches and cracks of rolling origin different in subsequent months, which indicates that the specialty factors (causes) acted on the rolling process, that have caused a lack of predictability in the number of these non-conformities. In turn, paying attention to the total number of all non-conformities in months, we can see the high repeatability of results. The steelworks' production system generated a similar number of member non-conformities each month $(262 \pm 3)$, with the difference that the number of non-conformities of skewness of the bar, wrinkle scratches, cracks of rolling origin rods in the following months varied greatly. Correlation analysis showed statistically significant relationships, as it turned out, cause-and-effect relationships between selected non-conformities.

Statistics give you the power to discover dependencies in data that cannot be seen with the naked eye, or it is difficult to see them by building a simple graph. Static analysis of data on non-conformance of bars allowed to obtain information on the structure of non-conformance, mutual relations, which were used to improve the production process and the quality of the finished product in the steel mill.

\section{REFERENCES}

[1] ISO 9000:2015 Quality management system - Fundamentals and vocabulary.

[2] TRICKER, R. ISO 9001:2015 for Small Businesses. London (UK): Taylor \& Francis Ltd, 2016.

[3] HOYLE, D. ISO 9000 Quality Systems Handbook-updated for the ISO 9001: 2015 standard: Increasing the Quality of an Organization's Outputs. London (UK): Taylor \& Francis Ltd, 2017.

[4] BORKOWSKI, S., KNOP, K., MIELACZAREK, K. The Use of Six Sigma indicators for Measurement the Process Quality of Products' Conformity Assessment in the Alternative Control. In: BORKOWSKI, S., KONSTANCIAK, M., eds. Quality Control as Process Improvement Factor. Czestochowa: Oficyna Wydawnicza Stowarzyszenia Menedżerów Jakości i Produkcji, 2012, pp. 116-131.

[5] KOWALIK, K. Six Sigma as a Method of Improving the Quality of Service Process. Production Engineering Archives. 2018, Vol. 19, pp. 10-15.

[6] PSAROMMATIS, F., MAY, G., DREYFUS, P.A., KIRITSIS, D. Zero defect manufacturing: state-of-the-art review, shortcomings and future directions inresearch. International Journal of Production Research. 2020, vol. 58, iss. 1, pp. 1-17.

[7] GÓRSKA, M. Application of FMEA to Predict Nonconformities Occurring in the Manufacture of Pipe. In METAL 2017: 26th International Conference on Metallurgy and Materials. Ostrava: TANGER, 2017, p. 178.

[8] TARÍ, J.J., SABATER, V. Quality tools and techniques: Are they necessary for quality management?. International Journal of Production Economics. 2004, vol. 92, iss. 3, pp. 267-280.

[9] PRÍSTAVKA, M., KOTOROVÁ, M., SAVOV, R. Quality control in production processes. Acta Technologica Agriculturae. 2016, 3, pp. 77-83.

[10] KNOP, K. Statistical Analysis of Responses Concerning the Importance of Human and Production or Services Issues in Various Companies. Production Engineering Archives. 2015, vol. 7, no 2, pp. 40-44.

[11] MURSKI, C., O'DONNEL, R. Defects of rolled products (in Polish). Katowice: Wydaw. Górniczo-Hutnicze, 1955. 